\title{
Immunohistochemical Localization of Some Neurotrophic Factors and Their Receptors in the Rat Carotid Body
}

\author{
Dimitrinka Y. Atanasova ${ }^{1,2}$, Nikolai E. Lazarov ${ }^{1,3^{*}}$ \\ ${ }^{1}$ Institute of Neurobiology, Bulgarian Academy of Sciences, Sofia, Bulgaria; ${ }^{2}$ Institute of Experimental Morphology, Pathology and \\ Anthropology with Museum, Bulgarian Academy of Sciences, Sofia, Bulgaria; ${ }^{3}$ Department of Anatomy and Histology, Medical \\ University of Sofia, Sofia, Bulgaria. \\ Email: *nlazarov@medfac.acad.bg
}

Received October $14^{\text {th }}, 2013$; revised November $10^{\text {th }}, 2013$; accepted December $5^{\text {th }}, 2013$

Copyright (C) 2013 Dimitrinka Y. Atanasova, Nikolai E. Lazarov et al. This is an open access article distributed under the Creative Commons Attribution License, which permits unrestricted use, distribution, and reproduction in any medium, provided the original work is properly cited.

\begin{abstract}
The carotid body (CB) is a small neural crest-derived organ that registers oxygen and glucose levels in blood and regulates ventilation. The most abundant cell type in the CB glomeruli is glomus or type I cells, which is enveloped by processes of sustentacular or type II cells. Growth and neurotrophic factors have been established as signaling molecules played an important role in the development of the CB. To gain insight whether these signaling molecules are present in the adult rat $\mathrm{CB}$, we examined the expression and cellular localization of some neurotrophic factors and their corresponding receptors in this organ by immunohistochemistry. The results showed the presence of nerve growth factor (NGF), brain-derived neurotrophic factor (BDNF), glial cell line-derived neurotrophic factor (GDNF) as well as p75 ${ }^{\mathrm{NTR}}$, tyrosine kinase A receptor (TrkA), tyrosine kinase B receptor (TrkB) and GDNF family receptor alpha1 (GFR $\alpha 1$ ) in the adult CB. At the light-microscopical level, the immunoreactivity for NGF and both its low-affinity (p75) and high-affinity (TrkA) receptors was detected in the majority of glomus cells and also in a subset of sustentacular cells. BDNF and its receptors, p75 and TrkB, were observed in the glomus cells, too. Remarkably, the immunohistochemical analysis revealed that the neuron-like glomus cells, but not the glial-like sustentacular cells, expressed GDNF and GFR $\alpha 1$. Taken together with prior results, it can be inferred that neurotrophins may be involved in the CB cell differentiation and survival in adulthood, and may exert a potent glomic protective action as well. It is also presumable that GDNF production by glomus cells plays a pivotal role in permitting long-term viability of CB grafts, which permits their potential applicability in cell therapy as a promising tool in neurodegenerative disorders.
\end{abstract}

Keywords: Carotid Body; Immunohistochemistry; Neurotrophin Receptors; Trophic Factors; Rat

\section{Introduction}

The carotid body $(\mathrm{CB})$ is the main peripheral arterial chemoreceptor that detects blood levels of $\mathrm{O}_{2}, \mathrm{CO}_{2} / \mathrm{H}^{+}$ and glucose, and responds to their changes by regulating breathing $[1,2]$. It is a small ovoid mass of tissue bilaterally located at the bifurcation of the common carotid artery, just before blood chemicals reach the brain, an organ that is excessively sensitive to oxygen and glucose deprivation. The CB is composed of two juxtaposed cell types, neuron-like type I or glomus cells and glial-like type II, also known as sustentacular cells, which are aggregated in richly vascularized cell clusters, called glomeruli [3]. Chemical and electrical synapses between these cells allow for complex sensory processing in the

"Corresponding author. organ [2]. Furthermore, the principal type cells, i.e., the glomus cell, contain secretory granules packed with putative transmitters and are thus considered the chemosensory cells of the organ $[1,4]$, while the type II cells, in addition to their supporting role, have recently been assumed to be the CB stem cells [5]. The neural crest origin of the $\mathrm{CB}$ suggests that it may require a trophic support for a continued survival and cell differentiation.

It has been demonstrated that $\mathrm{CB}$ chemosensitivity to hypoxia develops during the early postnatal period. This functional maturation partially depends on structural and neurochemical changes, which are promoted by some neurotransmitters, trophic factors and their receptors, acting on the $\mathrm{CB}$ cell population in autocrine or paracrine ways [6-8]. Besides, there is a convincing evidence that neurotrophic factors from $\mathrm{CB}$ cells and nerve fibers also 
play an important role in maintaining the structural and functional specialization of both $\mathrm{CB}$ components in adulthood [9]. Indeed, recent studies have revealed that glomus cells in the adult rat, of a neural crest origin, express a number of growth factors, implying their paracrine-autocrine role in the $\mathrm{CB}[10,11]$.

In order to determine the survival requirements of the parenchymal cells in this organ in adult life, we examined the immunohistochemical distribution and cellular localization of some neurotrophic factors and their corresponding receptors in the $\mathrm{CB}$ of normal adult rats.

\section{Materials and Methods}

\subsection{Animals and Tissue Preparation}

The experiments were carried out on male Wistar rats ( $300 \mathrm{~g}$ body weight). The experiments were conducted in accordance with the ethical guidelines of the EU Directive 2010/63/EU for the protection of animals used for scientific purposes following a standard protocol established by the Bioethical Commission of the Biomedical Research at the Institute of Neurobiology of the Bulgarian Academy of Sciences. All efforts were made to minimize the number of animals used and their suffering.

The rats were deeply anesthetized with Nembutal (50 $\mathrm{mg} / \mathrm{kg}$, i.p., Abbott) and transcardially perfused first with $0.05 \mathrm{M}$ phosphate buffered saline (PBS), followed by $4 \%$ paraformaldehyde in $0.1 \mathrm{M}$ phosphate buffer (PB), $\mathrm{pH}$ 7.3. After perfusion, the carotid bifurcations were quickly removed, both CBs were immediately dissected out and the specimens were postfixed in the same fixative overnight at $4^{\circ} \mathrm{C}$. Thereafter, the tissue blocks were embedded in paraffin and cut into $7 \mu \mathrm{m}$ thick sections.

\subsection{Immunohistochemical Procedure}

The sections of CBs were deparaffinized with xylene and ethanol, and processed for $\mathrm{ABC}$ (avidin-biotin-horseradish peroxidase complex) immunohistochemistry to determine the neurotrophin profile of their chemoreceptor elements. Briefly, the endogenous peroxidase was blocked with $1.2 \%$ hydrogen peroxide in absolute methanol, followed by antigen retrieval in $10 \mathrm{mM}$ citrate buffer ( $\mathrm{pH} \mathrm{6.0)}$ for up to $30 \mathrm{~min}$ in a microwave oven. After washing in PBS, the sections were preincubated for $60 \mathrm{~min}$ at room temperature in $5 \%$ normal goat serum to avoid unspecific staining. Between the separate steps, the sections were rinsed with cold PBS/Triton X-100. Subsequently, they were incubated in a humid chamber overnight at $4^{\circ} \mathrm{C}$ with the respective primary antibodies (see Table 1 for suppliers and working dilutions). After rinsing in PBS, the sections were incubated for $2 \mathrm{~h}$ at room temperature with the appropriate secondary antibody, biotinylated goat anti-rabbit IgG (Dianova, Hamburg, Germany), goat anti-mouse IgG or rabbit anti-goat IgG (both from Vector Laboratories, Burlingame, CA, USA), at a dilution of 1:500, 1:250 or 1:200, respectively. Following rinsing, the $\mathrm{ABC}$ complex (Vectastain Elite Kit; Vector) was applied. After a color development with diaminobenzidine as a chromogen for 3 to $5 \mathrm{~min}$, the sections were dehydrated in graded alcohols, cleared in xylene, coverslipped with Entellan and air-dried.

\subsection{Antisera Specificity Tests}

We applied positive and negative controls to test the specificity of the antibodies used in this study. For immunoreaction specificity testing, omission of the specific primary antibodies by their replacement with PBS or non-immune serum, at the same dilution as the primary antiserum, was performed and no specific immunostaining was found under these conditions. The specificities of the antibodies used in this study have been described in detail previously [12]. In particular, the primary antisera

Table 1. Primary antibodies used for immunohistochemistry.

\begin{tabular}{ccccc}
\hline Primary antiserum (Antigen) & Host species/Type & Supplier & Cat. № & Working dilution \\
\hline NGF & rabbit/polyclonal & Santa Cruz & sc-548 & $1: 500$ \\
BDNF & rabbit/polyclonal & Santa Cruz & sc-546 & $1: 500$ \\
NT-3 & goat/polyclonal & Santa Cruz & sc-13380 & $1: 500$ \\
GDNF & mouse/monoclonal & Santa Cruz & sc-13147 & $1: 500$ \\
GFR $\alpha 1$ & rabbit/polyclonal & Santa Cruz & sc-10716 & $1: 500$ \\
p75 & mouse/monoclonal & DAKO & M 3507 & $1: 200$ \\
TrkA & rabbit/polyclonal & Santa Cruz & sc-118 & $1: 500$ \\
TrkB & rabbit/polyclonal & Santa Cruz & sc- 8316 & $1: 500$ \\
TrkC & rabbit/ polyclonal & Santa Cruz & sc-117 & $1: 500$ \\
\hline
\end{tabular}


were preabsorbed for $2 \mathrm{~h}$ at room temperature or for $24 \mathrm{~h}$ at $4^{\circ} \mathrm{C}$ with the respective synthetic antigen at a concentration of 20 or $200 \mu \mathrm{g} / \mathrm{ml}$ antiserum at its working dilution and the preabsorbed antisera were substituted for non-absorbed antisera in the immunohistochemical procedure. Preabsorbed antibodies failed to stain any tissues of the CB. The antibodies were further characterized with tissue from regions known to contain the studied antigens. Immunolabeled sections of various brain regions at the level of the trigeminal sensory nuclear complex and the trigeminal ganglion were used as positive controls for each of the tested neurotrophic factors.

\subsection{Image Processing and Analysis}

After immunostaining, the specimens were examined and photographed with a Nikon research microscope equipped with a DXM1200c digital camera. The digital images were saved in a TIF format, and matched for brightness, contrast and removal of artifacts using Adobe Photoshop CS3 software (Adobe Systems, Inc., San Jose, CA). The number of immunopositive cells was determined in a semiquantitative way for the two given cell populations. The resultant values provide a relative quantity of the immunostained glomus and sustentacular cells.

\section{Results}

\subsection{Nerve Growth Factor Family}

This small family of neurotrophic factors consists of a group of neurotrophins, including the nerve growth factor (NGF), brain-derived neurotrophic factor (BDNF), neurotrophin-3 (NT-3) and neurotrophin-4 (NT-4, also known as NT-5). They promote neuronal differentiation, survival and plasticity by signaling via both a common low-affinity (pan)neurotrophin receptor $\mathrm{p} 75^{\mathrm{NTR}}$ and highaffinity transmembrane receptors belonging to the tyrosine receptor kinase (Trk) proto-oncogene family. The latter include TrkA, TrkB and TrkC, and exhibit binding specificity. TrkA is a specific receptor for the NGF, TrkB is a receptor for the BDNF and NT-4, while TrkC is a receptor for NT-3. The number of immunopositive cells and relative expression levels of the examined neurotrophins and their receptors are summarized in Table 2.

Our experiments showed that the majority of the adult glomus cells and a subset of the sustentacular cells in the rat CB were NGF immunopositive (Figure 1(A)). The immunoreactive cells were spread throughout the CB. The immunostaining in the glomus cells was strong while that in the sustentacular cells was moderate and primarily localized in their cytoplasmic processes surrounding the glomus cells. None of the immunopositive cells showed staining in their nuclei. Further, immunoreactivity for p75 (Figure 1(B)) and TrkA (Figure 1(C))
Table 2. Distributional pattern and relative expression levels of neurotrophins and their receptors in the adult rat carotid body.

\begin{tabular}{|c|c|c|c|c|c|}
\hline \multicolumn{2}{|c|}{ Neurotrophic factors } & NGF & BDNF & NT3 & GDNF \\
\hline Glomus cells & & +++ & +++ & +++ & +++ \\
\hline Sustentacular cells & & + & + & + & - \\
\hline $\begin{array}{l}\text { Neurotrophin } \\
\text { receptors }\end{array}$ & $\mathrm{p} 75^{\mathrm{NTR}}$ & TrkA & TrkB & TrkC & GFR $\alpha 1$ \\
\hline Glomus cells & +++ & +++ & +++ & +++ & +++ \\
\hline Sustentacular cells & + & + & + & - & + \\
\hline
\end{tabular}

$(-)$, no immunopositive cells observed; $(+),<50 \%$ immunopositive cells; $(++), 50 \%-90 \%$ immunopositive cells; $(+++),>90 \%$ immunopositive cells.

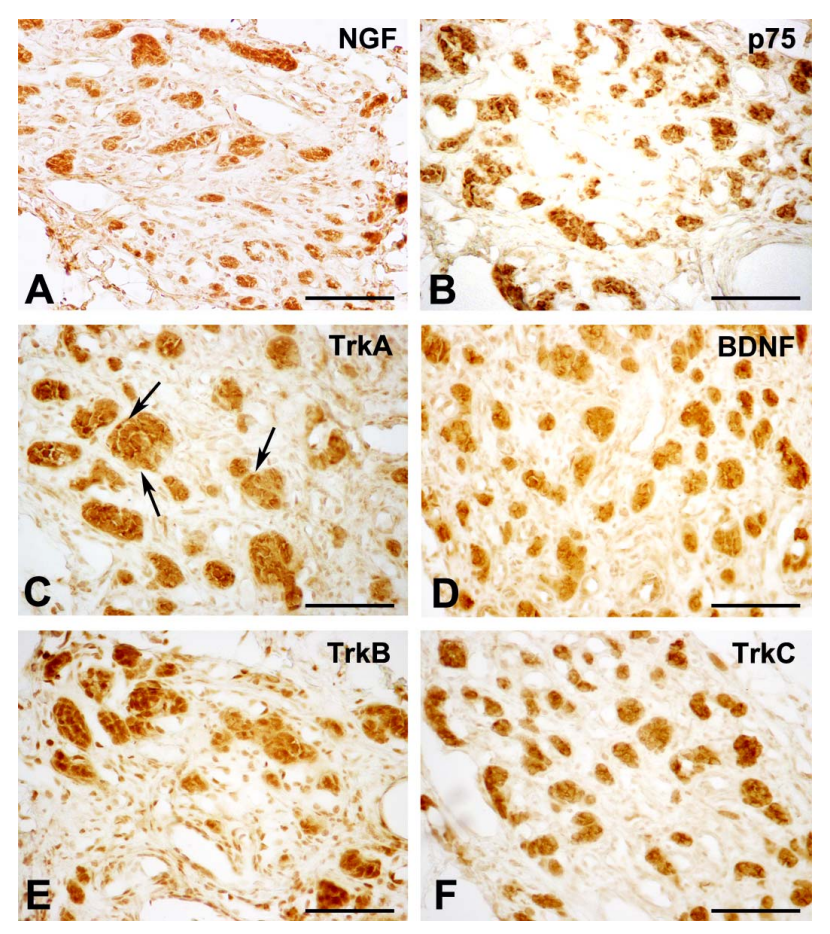

Figure 1. Immunohistochemical demonstration of members of the NGF family and their receptors in the $C B$ of adult rats. Light photomicrographs showing that the cell clusters exhibit immunoreactivity for NGF (A) and its low-affinity $\mathrm{p}^{\mathrm{NTR}}$ (B) and high-affinity TrkA (C) receptors. Note that the immunostaining is observed in the cytoplasm of a large number of glomus cells and in a subset of sustentacular cells. The cytoplasmic processes of the latter are also endowed with TrkA receptor (arrows). (D) Intense BDNF immunoreactivity in numerous glomus cells and scattered sustentacular cells. Expression of TrkB (E) and TrkC (F) receptor subtypes is seen in virtually all glomus cells. Scale bar $=50 \mu \mathrm{m}$.

was detected in most of the glomus and in some sustentacular cells, as well as in nerve fibers within and around the cell clusters. Similarly, NT-3 (not shown) and BDNF immunostaining was observed in a lot of glomus cells and a few sustentacular cells in the CB glomeruli (Figure 
1(D)). In addition, almost all glomus cells were richly endowed with TrkB (Figure 1(E)) and TrkC (Figure 1(F)) receptors.

\subsection{Glial Cell Line-Derived Neurotrophic Factor Family}

Using antibodies directed against the glial cell line-derived neurotrophic factor (GDNF) and its receptors, we identified a large number of immunoreactive cells in the $\mathrm{CB}$, typically aggregated in evenly distributed cell clusters. In particular, virtually all glomus (type I) cells in the CB were immunopositive for GDNF (Figure 2(A)), with no notable labeling of the elongated sustentacular (type II) cells, which surrounded the glomeruli. Accordingly, all groups of BDNF-immunoreactive cells were also immunostained for the GDNF family receptor alpha-1 (GFR $\alpha 1$ ), which specifically binds the GDNF (Figure 2(B)). Our attempts to detect RET protein expression by

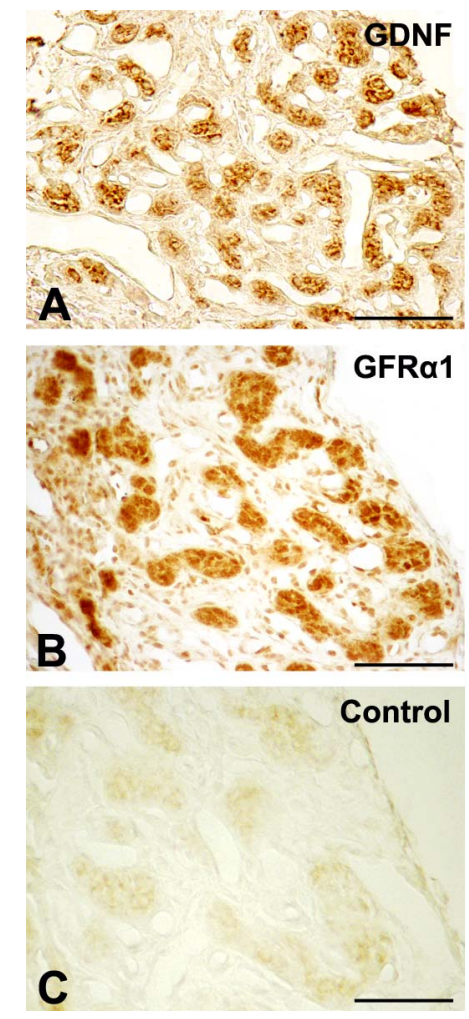

Figure 2. Immunohistochemical demonstration of GDNF and its specific receptor in the $\mathrm{CB}$ of adult rats. (A) Representative photomicrograph indicating the presence of GDNF-immunoreactive cell groups in the CB glomeruli. Note that only the glomus cells are immunopositive. (B) High-resolution micrograph showing the expression of GFRa1 receptor in the adult $C B$. A large number of type $I$ cells exhibit strong immunoreactivity for this receptor subtype with similar distributional patterns. (C) No immunoreactivity is observed in the section incubated with a preabsorbed primary antibody. Scale bars $=50 \mu \mathrm{m}$. immunohistochemistry have failed so far, probably because its localization is mostly restricted to nerve endings which are very few in the CB.

Control sections treated with the primary antisera preabsorbed with the respective synthetic antigens did not display any staining (Figure 2(C)).

\section{Discussion}

The $\mathrm{CB}$ is the major arterial oxygen sensor providing essential afferent input required for the maintenance of breathing. There is compelling evidence that neurotrophic factors such as BDNF and GDNF, working in tandem, are important regulators for the development of peripheral chemoafferent neurons; the latter provide hypoxic drive to the brainstem respiratory network [13, 14]. Previous studies have shown that many growth and trophic factors are present in the glomus type I cells of the mammalian CB (for a recent review, see [9]). Our results provide immunohistochemical evidence that the parenchymal cells in the adult rat $\mathrm{CB}$ express certain neurotrophins belonging to the NGF and GDNF families as well as their corresponding receptors. In particular, here we demonstrate the occurrence of NGF, BDNF, NT-3 and GDNF proteins in the vast majority of glomus cells and a subset of sustentacular cells which are also endowed with their cognate receptors $\mathrm{p} 75$, TrkA, TrkB and GFR $\alpha 1$. Such expressional patterns are consistent with the conclusion that the glomus cells may exert trophic and/or regulatory impact on the adjacent $\mathrm{CB}$ cells in adult life through neurotrophins, which play autocrine and/or paracrine roles in promoting the survival, growth and maturation of these cells $[11,15]$.

In addition to their established role in maintaining the structural and functional specialization of the $\mathrm{CB}$ in adulthood, available evidence strongly suggests that neurotrophins also promote neuronal precursor cell proliferation and differentiation of distinct neural crest-derived cells (see [16] and references therein). Indeed, glomus and sustentacular cells, like sympathetic neurons and chromaffin cells of the adrenal medulla, originate from the neural crest and phenotypically resemble sympathoadrenal chromaffin cells $[17,18]$. Our data confirm prior findings demonstrating that NGF and its high-affinity receptor TrkA are preferentially expressed by the $\mathrm{CB}$ glomus cells [10]. However, there is evidence that the glomus cells do not depend on NGF (as do sympathetic neurons) for survival in vitro and, thus, their growth requirements are different from other cells of neural crest origin [19]. In this respect, it has been proposed that NGF interacts cooperatively with the basic fibroblast growth factor to promote proliferation and survival of the CB cell population [20]. We have further shown that NGF and TrkA immunoreactivity also occurs 
in the sustentacular cells of the rat CB. It is well known that NGF is an essential growth factor supporting stem cell self-renewal outside the nervous system and, thus, serves as a potential marker for progenitor cells. This could explain the occurrence of immunoreactivity for this neurotrophin and its receptors also in the sustentacular cells which have lately been proposed to be the CB stem cells giving rise to new glomus cells upon hypoxia [5, 21].

Several recent reports suggest that the expression of BDNF, GDNF and their receptors in virtually all glomus cells, which are known to be highly dopaminergic [22], might account for their potential applicability in neurological cell therapy [23-26]. Moreover, it has been shown that nerve fibers innervating the $\mathrm{CB}$ and dopaminergic neurons in the rat petrosal ganglion (PG) also exhibit BDNF immunoreactivity [27]. Hence, it is plausible to assume that BDNF and GDNF potently promote the survival of dopaminergic neurons like CB glomus cells, and also exert a trophic effect on chemoafferent neurons of the PG, acting as a target-derived survival factor in adult life $[27,28]$. It has also been proposed that BDNF selectively produced by glomus cells may support local vascular morphogenesis in the CB [27] whereas GDNF may act as a protector of catecholaminergic neurons against toxic damage and oxidative stress [29]. In line with this, we were able to demonstrate the presence of GFR $\alpha 1$ in glomus cells of the adult rat CB whose presence in them was also confirmed by RT-PCR [23]. It is likely that BDNF acts mainly via its specific receptor in the adult rat $\mathrm{CB}$.

Unlike the other neurotrophic factors of the NGF family, NT-3 and NT-4 have been examined in less detail in the adult rat $\mathrm{CB}$. In the present study, we demonstrated the presence of NT-3 and its specific receptor TrkC, but not of NT-4, in the CB glomeruli. Nonetheless, we were able to show that TrkB, which is a common receptor for the BDNF and NT-4, is expressed in almost all glomus cells. Besides, it is well known that NT-3 binds, though with less affinity, to other related Trk receptors, TrkA and TrkB, as well $[16,30]$. Accordingly, it seems that the survival of glomus cells also depends on TrkB signaling. The source of this signaling is, however, still remains unidentified.

\section{Conclusion}

In conclusion, it can be inferred that the majority of the glomus cells and a subset of the sustentacular cells in the adult rat $\mathrm{CB}$ contain high levels of NGF, BDNF and GDNF and their corresponding receptors. Taken together, our results suggest that the principal $\mathrm{CB}$ cells depend on certain locally produced trophic factors for their survival in adult life. It is possible, however, that other neurotro- phic factors previously reported to be present in the rat $\mathrm{CB}[9,11]$ also play a role as survival factors for the natural CB cell populations in adulthood. Given that survival depends on cell-cell interactions, glomus cells may exert via the entire cocktail of neurotrophins present in the trophic and/or regulatory control on the adjacent neuron-like and glial-like cells in the $\mathrm{CB}$, thus implying their autocrine and paracrine action. Last but not least, neurotrophins and in particular GDNF might prove to be good candidates for the maintenance of the long-term viability of CB grafts, thus permitting the successful development of neurological cell replacement therapy. However, additional experimental and clinical studies are needed to determine whether this animal model is applicable in humans.

\section{Acknowledgements}

This work was financially supported by the European Social Fund and Republic of Bulgaria, Operational Programme "Development of Human Resources" 20072013 framework (grant BG051PO001-3.3.060048 from 04.10.2012 to DA). The authors wish to thank Professor Anton Tonchev (Medical University of Varna) for the generous gift of the primary antibodies, and Dr Angel Dandov for his critical reading of this manuscript.

\section{REFERENCES}

[1] C. Gonzalez, L. Almaraz, A. Obeso and R. Rigual, "Carotid Body Chemoreceptors: From Natural Stimuli to Sensory Discharges," Physiological Reviews, Vol. 74, No. 4, 1994, pp. 829-898.

[2] C. A. Nurse and N. A. Piskuric, "Signal Processing at Mammalian Carotid Body Chemoreceptors," Seminars in Cell \& Developmental Biology, Vol. 24, No. 1, 2013, pp. 22-30. http://dx.doi.org/10.1016/j.semcdb.2012.09.006

[3] D. Y. Atanasova, M. E. Iliev and N. E. Lazarov, "Morphology of the Rat Carotid Body," Biomedical Reviews, Vol. 22, 2011, pp. 41-55.

[4] C. A. Nurse, "Neurotransmission and Neuromodulation in the Chemosensory Carotid Body," Autonomic Neuroscience, Vol. 120, No. 1-2, 2005, pp. 1-9. http://dx.doi.org/10.1016/j.autneu.2005.04.008

[5] R. Pardal, P. Ortega-Sáenz, R. Durán and J. López-Barneo, "Glia-Like Stem Cells Sustain Physiologic Neurogenesis in the Adult Mammalian Carotid Body," Cell, Vol. 131, No. 2, 2007, pp. 364-377. http://dx.doi.org/10.1016/j.cell.2007.07.043

[6] J. López-Barneo, P. Ortega-Sáenz, R. Pardal, A. Pascual and J. I. Piruat, "Carotid Body Oxygen Sensing," European Respiratory Journal, Vol. 32, No. 5, 2008, pp. 1386-1398.

http://dx.doi.org/10.1183/09031936.00056408

[7] A. Bairam and J. L. Carroll, "Neurotransmitters in Carotid Body Development," Respiratory Physiology and 
Neurobiology, Vol. 149, No. 1-3, 2005, pp. 217-232. http://dx.doi.org/10.1016/j.resp.2005.04.017

[8] R. De Caro, V. Macchi, M. M. Sfriso and A. Porzionato, "Structural and Neurochemical Changes in the Maturation of the Carotid Body," Respiratory Physiology \& Neurobiology, Vol. 185, No. 1, 2013, pp. 9-19. http://dx.doi.org/10.1016/i.resp.2012.06.012

[9] A. Porzionato, V. Macchi, A. Parenti and R. De Caro, "Trophic Factors in the Carotid Body," International Review of Cell \& Molecular Biology, Vol. 269, 2008, pp. 158. http://dx.doi.org/10.1016/S1937-6448(08)01001-0

[10] M. Yamamoto and S. Iseki, "Co-Expression of NGF and Its High-Affinity Receptor TrkA in the Rat Carotid Body Chief Cells," Acta Histochemica et Cytochemica, Vol. 36, No. 4, 2003, pp. 377-383. http://dx.doi.org/10.1267/ahc.36.377

[11] A. Izal-Azcárate, S. Belzunegui, W. San Sebastián, P. Garrido-Gil, M. Vázquez-Claverie, B. López, I. Marcilla and M. Luquin, "Immunohistochemical Characterization of the Rat Carotid Body," Respiratory Physiology \& Neurobiology, Vol. 161, No. 1, 2008, pp. 95-99. http://dx.doi.org/10.1016/j.resp.2007.12.008

[12] A. B. Tonchev, T. Yamashima, J. Guo, G. N. Chaldakov and N. Takakura, "Expression of Angiogenic and Neurotrophic Factors in the Progenitor Cell Niche of Adult Monkey Subventricular Zone," Neuroscience, Vol. 144, No. 4, 2007, pp. 1425-1435. http://dx.doi.org/10.1016/j.neuroscience.2006.10.052

[13] D. M. Katz, "Neuronal Growth Factors and Development of Respiratory Control," Respiratory Physiology \& Neurobiology, Vol. 135, No. 2-3, 2003, pp. 155-165. http://dx.doi.org/10.1016/S1569-9048(03)00034-X

[14] D. M. Katz, "Regulation of Respiratory Neuron Development by Neurotrophic and Transcriptional Signaling Mechanisms," Respiratory Physiology \& Neurobiology, Vol. 149, No. 1-3, 2005, pp. 99-109. http://dx.doi.org/10.1016/j.resp.2005.02.007

[15] Z. Y. Wang and G. E. Biscard, "Postnatal Growth of the Carotid Body," Respiratory Physiology \& Neurobiology, Vol. 149, No. 1-3, 2005, pp. 181-190. http://dx.doi.org/10.1016/j.resp.2005.03.016

[16] E. J. Huang and L. F. Reichardt, "Neurotrophins: Roles in Neuronal Development and Function," Annual Review of Neuroscience, Vol. 24, 2001, pp. 677-736. http://dx.doi.org/10.1146/annurev.neuro.24.1.677

[17] A. G. E. Pearse, J. M. Polak, F. W. Rost, J. Fontaine, C. Le Lièvre and N. Le Douarin, "Demonstration of the Neural Crest Origin of Type I (APUD) Cells in the Avian Carotid Body, Using a Cytochemical Marker System," Histochemie, Vol. 34, No. 3, 1973, pp. 191-203. http://dx.doi.org/10.1007/BF00303435

[18] N. Le Douarin, "The Neural Crest," Cambridge University Press, London, 1982.

[19] M. C. Fishman and A. E. Schaffner, "Carotid Body Cell Culture and Selective Growth of Glomus Cells," American Journal of Physiology, Vol. 246, No. 1 Pt 1, 1984, pp. C106-C113.
[20] C. A. Nurse and C. Vollmer, "Role of Basic FCF and Oxygen in Control of Proliferation, Survival, and Neuronal Differentiation in Carotid Body Chromaffin Cells," Developmental Biology, Vol. 184, No. 2, 1997, pp. 197206. http://dx.doi.org/10.1006/dbio.1997.8539

[21] R. Pardal, P. Ortega-Sáenz, R. Durán, A. Platero-Luengo and J. López-Barneo, "The Carotid Body, a Neurogenic Niche in the Adult Peripheral Nervous System," Archives Italiennes de Biologie, Vol. 148, No. 2, 2010, pp. 95-105.

[22] D. Atanasova and N. Lazarov, "Dopamine and Dopaminergic Innervation of the Rat Carotid Body," Comptes Rendus de l'Académie Bulgare des Sciences, Vol. 64, No. 5, 2011, pp. 751-756.

[23] J. J. Toledo-Aral, S. Méndez-Ferrer, R. Pardal, M. Echevarría and J. López-Barneo, "Trophic Restoration of the Nigrostriatal Dopaminergic Pathway in Long-Term Carotid Body-Grafted Parkinsonian Rats," Journal of Neuroscience, Vol. 23, No. 1, 2003, pp. 141-148.

[24] J. Villadiego, S. Méndez-Ferrer, T. Valdés-Sánchez, I. Silos-Santiago, I. Fariñas, J. López-Barneo and J. J. Toledo-Aral, "Selective Glial Cell Line-Derived Neurotrophic Factor Production in Adult Dopaminergic Carotid Body Cells in Situ and after Intrastriatal Transplantation," Journal of Neuroscience, Vol. 25, No. 16, 2005, pp. 4091-4098. http://dx.doi.org/10.1523/JNEUROSCI.4312-04.2005

[25] J. López-Barneo, R. Pardal, P. Ortega-Sáenz, R. Durán, J. Villadiego and J. J. Toledo-Aral, "The Neurogenic Niche in the Carotid Body and Its Applicability to Antiparkinsonian Cell Therapy," Journal of Neural Transmission, Vol. 116, No. 8, 2009, pp. 975-982.

http://dx.doi.org/10.1007/s00702-009-0201-5

[26] M. R. Luquin, M. Manrique, J. Guillén, J. Arbizu, C. Ordoñez and I. Marcilla, "Enhanced GDNF Expression in Dopaminergic Cells of Monkeys Grafted with Carotid Body Cell Aggregates," Brain Research, Vol. 1375, 2011, pp. 120127. http://dx.doi.org/10.1016/j.brainres.2010.12.033

[27] R. Brady, S. I. Zaidi, C. Mayer and D. M. Katz, "BDNF Is a Target-Derived Survival Factor for Arterial Baroreceptor and Chemoafferent Primary Sensory Neurons," Journal of Neuroscience, Vol. 19, No. 6, 1999, 21312142.

[28] J. T. Erickson, T. A. Brosenitsch and D. M. Katz, "BrainDerived Neurotrophic Factor and Glial Cell Line-Derived Neurotrophic Factor Are Required Simultaneously for Survival of Dopaminergic Primary Sensory Neurons in Vivo," Journal of Neuroscience, Vol. 21, No. 2, 2001, pp. 581-589.

[29] E. Arenas, M. Trupp, P. Akerud and C. F. Ibáñez, "GDNF Prevents Degeneration and Promotes the Phenotype of Brain Noradrenergic Neurons in Vivo," Neuron, Vol. 15, No. 6, 1995, pp. 1465-1473. http://dx.doi.org/10.1016/0896-6273(95)90024-1

[30] A. Patapoutian and L. F. Reichardt, "Trk Receptors: Mediators of Neurotrophin Action," Current Opinion in Neurobiology, Vol. 11, No. 3, 2001, pp. 272-280. http://dx.doi.org/10.1016/S0959-4388(00)00208-7 